Canadian Science Publishing

Biochemistry and Cell Biology

Biochimie et biologie cellulaire

\title{
Protein-surfactant interactions between bovine lactoferrin and sophorolipids under neutral and acidic conditions
}

\begin{tabular}{|r|l|}
\hline Journal: & Biochemistry and Cell Biology \\
\hline Manuscript ID & bcb-2016-0057.R2 \\
\hline Danuscript Type: & Article \\
\hline Complete List of Authors: & $\begin{array}{l}\text { Matsumiya, Kentaro; Kyoto University, Laboratory of Quality Analysis and } \\
\text { Assessment } \\
\text { Suzuki, Yasushi; Saraya Co. Ltd., Biochemical laboratory } \\
\text { Hirata, Yoshihiko; Saraya Co., Ltd, Biochemical Laboratory } \\
\text { Nambu, Yuko; Kyoto University } \\
\text { Matsumura, Yasuki; Kyoto University, Laboratory of Quality Analysis and } \\
\text { Assessment }\end{array}$ \\
\hline Keyword: & $\begin{array}{l}\text { Lactoferrin, Sophorolipids, Protein-surfactant interaction, Complex, } \\
\text { Electrostatic interaction }\end{array}$ \\
\hline \multicolumn{2}{|c|}{} \\
\hline
\end{tabular}


1 Protein-surfactant interactions between bovine lactoferrin and sophorolipids under 2 neutral and acidic conditions

3

4 Kentaro Matsumiya ${ }^{1}$, Yasushi A. Suzuki ${ }^{2}$, Yoshihiko Hirata ${ }^{2}$, Yuko Nambu ${ }^{1}$, Yasuki $5 \quad$ Matsumura $^{1}$

$6{ }^{1}$ Graduate School of Agriculture, Kyoto University, Japan, ${ }^{2}$ Lactoferrin Laboratory, 7 Saraya Co.,Ltd., Japan

8

9 *To whom correspondence should be addressed. Tel: +81-774-38-3748. Fax: +81-774-

10 38-3746. Email: matumiya@kais.kyoto-u.ac.jp

11 Mailing address: Laboratory of Quality Analysis and Assessment, Division of 12 Agronomy and Horticultural Science, Graduate School of Agriculture, Kyoto University,

13 Gokasho, Uji, Kyoto 611-0011, Japan 
1 Abstract

2 In order to understand the protein-surfactant interactions between naturally derived

3 sophorolipids (SLs) and bovine lactoferrin (bLf), we carried out spectroscopic, 4 microscopic, and biochemical experiments under weakly acidic and neutral $\mathrm{pH}$

5 conditions. Particle size analysis, microscopy, and enzymatic digestion indicated that

6 bLf and SLs interact with each other to form sheet-like and small aggregated structures

7 reflecting the original self-organization of SLs at $\mathrm{pH} 5.0$ and 7.0, respectively. Circular

8 dichroism (CD) showed that SLs did not significantly affect the secondary structure of

9 bLf.

11 Keywords

12 Lactoferrin; Sophorolipids; Protein-surfactant interaction; Complex; Electrostatic 13 interaction

1. Introduction

Lactoferrin, first discovered in bovine milk, is a red-colored glycoprotein that can bind iron ions with high affinity (Sørensen and Sørensen 1939; Groves 1960). Bovine lactoferrin (bLf) is a single-chain protein consisting of 689 amino acid residues, with a molecular weight of 78,000 Da and an isoelectric point of $\mathrm{pH} 8.8$ (Moore et al.

20 1997; Shimazaki 1993). Since lactoferrin is associated with a diverse range of 21 biochemical functions, it is widely accepted that it is a multi-functional protein that can be used in the manufacture of different products including foods, drugs, and cosmetics.

23 Some of its important biological functions include anti-inflammatory activity, 24 bacteriostatic activity, growth factor action, and bone formation (Lönnerdal 2013). 
1 Amongst the various functions of lactoferrin, researchers have particularly 2 focused on its role in stimulating skin keratinocyte function and wound 3 re-epithelialization, originally reported by Tang et al. (2010). In our previous study, we 4 demonstrated that bLf significantly increased tropoelastin expression in cultured 5 fibroblasts, and this expression is efficiently promoted by addition of a novel skin 6 penetration enhancer, acid-type SLs (Ishii et al. 2012). In the same study, we also 7 observed that on addition of SLs, transdermal absorption of bLf through a model skin 8 was enhanced up to 1.7-fold, possibly due to complex formation between bLf and SLs. 9 However, the exact protein-surfactant interactions remain to be understood. Acid-type SLs are produced from natural resources through fermentation by non-pathogenic yeast, Starmerella bombicola. These are surface-active glycolipids 12 comprising a sophorose unit, which is a glucose disaccharide, glycosically linked to a 13 hydroxyl fatty acid as shown in Fig. 1 (Lang 2003; Ishii et al. 2012). According to a 14 previous study, SL molecules tend to self-organize, forming giant twisted or helical ribbons in acidic conditions $(\mathrm{pH}<5.5)$ (Zhou et al. 2004). The yield of the solid ribbon-like products decreases with an increase in $\mathrm{pH}$, forming short-range ordered micelles under neutral conditions. In contrast, the sodium salt of acidic SLs (SLs-Na) spontaneously forms vesicles in a neutral aqueous solution, and these vesicles can incorporate triterpene glycosides and significantly improve the penetration of triterpene 20 glycosides through an in vitro skin model (Imura et al. 2014). In the current study, to investigate the protein-surfactant interactions between bLf and SLs, structural changes in bLf induced by SLs were analyzed using spectroscopic, microscopic, and biochemical methods. bLf-SL complexes formed at $\mathrm{pH}$ 5.0 (weakly acidic) and $\mathrm{pH} 7.0$ (neutral) were chosen as representative of efficient 
1 delivery agents of bLf in commonly used cosmetics and food products.

2

3 2. Materials and methods

$4 \quad$ 2.1. Materials

5

$6 \quad 0.1 \% \mathrm{NaCl}, 0.1 \%$ urea, and $0.25 \%$ yeast extract was fermented by Starmerella 7 bombicola (NBRC 10243) to produce a mixture of lactone-type and acid-type SLs. The 8 lactone-type SLs were chemically converted to the acid-type SLs, which were purified 9 as previously described (Zhou et al. 2004). The typical chemical structure of SLs used

in this study is shown in Fig. 1. The purity and chemical structure of the SLs were confirmed by NMR and liquid chromatography-mass spectrometry as previously described (Konishi et al. 2008 and Nuñez et al. 2000). bLf (purity > 95\%) was purchased from Morinaga Milk Industry Co., Ltd. (Tokyo, Japan). The iron saturation level of bLf ranged between $10 \%$ and $20 \%$ and LPS contamination was undetectable (manufacturer's specifications). Proteolytic enzymes proteinase $\mathrm{K}$ obtained from Tritirachium album (EC 3.4.21.64; catalogue No. 160-14001) and trypsin obtained from porcine pancreas (EC 3.4.21.4; catalogue No. 207-19183) were purchased from Wako Pure Chemical Industries, Ltd. (Osaka, Japan). All other chemicals used were of analytical grade.

\subsection{Experiments}

\subsubsection{Preparation of sample solutions}

bLf and SLs solutions were prepared by adding $0.2 \mathrm{wt} \%$ of bLf or SLs into 10 $\mathrm{mM}$ sodium citrate buffer solution ( $\mathrm{pH} 5.0$ ) or $10 \mathrm{mM}$ sodium phosphate buffer solution ( $\mathrm{pH}$ 7.0) followed by overnight incubation on an automatic shaker $(>12 \mathrm{~h})$ at ambient 
1 temperature to ensure complete dissolution. Sample solutions were prepared by gently

2 mixing the bLf and SLs solutions at a volume ratio of 1:1 and were subjected to assays

3 within $6 \mathrm{~h}$ of preparation. The approximate molar ratio of bLf and SLs was 1:125,

4 contingent on the most likely molecular weight of 78,000 Da for bLf and $622 \mathrm{Da}$ for

5 SLs.

$6 \quad$ 2.2.2. Particle size analysis

$7 \quad$ Particle size distribution of sample solutions was analyzed by dynamic light 8 scattering (DLS) at $25^{\circ} \mathrm{C}$ (Nicomp 370 submicron particle size analyzer (Particle Sizing

9 System, Inc., Santa Barbara, California, USA)) using the solid particle mode and

10 Nicomp distribution analysis mode assuming multi-modal distributions. A typical

11 particle size distribution is described in the results section. The particle size in the 12 dissolved sample solutions is also reported as volume-weighted mean particle diameter $13\left(d_{4,3}\right)$.

14 2.2.3. Cryo-scanning electron microscopy (Cryo-SEM)

15 Sample solutions were rapidly frozen in liquid nitrogen slush and quickly 16 transferred into the specimen chamber of a scanning electron microscope equipped with 17 a cryo-unit (S4100, Hitachi, Ltd., Tokyo, Japan). They were etched at $-65^{\circ} \mathrm{C}$ for $60 \mathrm{~min}$ 18 or longer to remove water molecules on the surface of frozen solutions and then sputter 19 coated with gold. All samples were observed at $-65^{\circ} \mathrm{C}$ with an acceleration voltage of $20 \quad 5.0 \mathrm{kV}$.

$21 \quad$ 2.2.4. Enzymatic digestion

22 Sample solutions were gently mixed with enzyme solutions containing 23 Proteinase K or trypsin at a volume ratio of 19:1 followed by incubation in a water bath 24 (with constant shaking) at $37^{\circ} \mathrm{C}$ for $90 \mathrm{~min}$. The enzymatic reactions were terminated by $-5-$ 
1 high-temperature heat treatment at $95^{\circ} \mathrm{C}$ for $20 \mathrm{~min}$. The enzymatically hydrolyzed

2 samples were analyzed by sodium dodecyl sulfate-polyacrylamide gel electrophoresis

3 (SDS-PAGE). SDS-PAGE was carried out on a gradient precast slab gel containing 5-

$420 \%$ acrylamide (e-PAGEL E-T520L, ATTO, Tokyo, Japan), followed by staining with

5 Coomassie brilliant blue.

$6 \quad$ 2.2.5. Surface hydrophobicity

$7 \quad$ Surface hydrophobicity of bLf was evaluated as described previously (Kato

8 and Nakai 1980; Hayakawa and Nakai 1985). In order to exclude the background

9 influence of SLs on fluorescence intensity, the SLs solutions were used as controls for

10 both bLf and SLs solutions. To prepare various concentrations of bLf and SLs solutions,

11 sample and control solutions were diluted with the corresponding buffer solution at a

12 volume ratio of $0: 25,3: 22,6: 19,9: 16$, and $12: 13$. Solutions were gently mixed with

13 1-anilinonaphthalene-8-sodium sulfonate (ANS-Na) in appropriate buffer solutions (8

$14 \mathrm{mg} / \mathrm{mL}$ ) at a volume ratio of $200: 1$ and incubated in a water bath at $25^{\circ} \mathrm{C}$ for $10 \mathrm{~min}$.

15 Using a fluorescence spectrophotometer, fluorescence intensity was recorded at a

16 wavelength of $470 \mathrm{~nm}$ with excitation at $390 \mathrm{~nm}$ (F-3000, Hitachi, Tokyo, Japan). The

17 hydrophobicity index was calculated from the slopes of the fluorescence intensity vs

18 sample concentration curves.

19 2.2.6. Circular dichroism (CD)

$20 \quad \mathrm{CD}$ spectroscopy was performed at $25^{\circ} \mathrm{C}$ on a spectropolarimeter using a quartz

21 cell with $0.1 \mathrm{~mm}$ optical path length (J-720, JASCO, Tokyo, Japan). The values were

22 expressed as the mean of the data obtained from three samples: each measurement was

23 repeated three times for each of the three samples. The mean residue ellipticity was

24 calculated according to the following equation (Fasman 1978): 


$$
[\theta]_{\lambda}=\frac{\theta_{o b s} \times M R W}{10 \times d \times c}
$$

1 where $\lambda=$ wavelength; $\theta_{\mathrm{obs}}=$ observed ellipticity in degrees; MRW = mean residue

2 weight of repeating unit; $c=$ concentration in grams per milliliter; $d=$ path length in 3 centimeters.

4 2.2.7. Statistics

5 All experiments were conducted in triplicate with freshly prepared sample

6 solutions. Mean values and standard deviations of the triplicate measurements are

7 shown unless otherwise stated. Statistical analyses were performed using Microsoft

8 Excel ver. 2013 for Windows.

9

3. Results and discussion

3.1. Particle size analysis

To analyze the particle size distribution of the sample solutions containing 0.1 $\mathrm{wt} \%$ of $\mathrm{bLf}$ and/or $0.1 \mathrm{wt} \%$ of SLs, DLS measurements were carried out using the particle size analyzer at $25{ }^{\circ} \mathrm{C}$. Under weakly acidic condition, the particle size of bLf was approximately $10 \mathrm{~nm}$ (Fig. 2a), indicating that bLf completely dissolved in the solution with $\mathrm{pH}$ 5.0. In contrast, SLs seemed to form large aggregates of about 1,200 $\mathrm{nm}$ in the $\mathrm{pH} 5.0$ solution (Fig. 2b), as described previously (Zhou et al. 2004). When bLf and SLs were mixed at a weight ratio of 1:1, the mono-modal peak originating from the dissolved bLf disappeared, and aggregates slightly larger than the SLs aggregates, probably consisting of SLs and bLf, were observed (Fig. 2c). These results show that bLf and SLs interact with each other and probably form complexes at $\mathrm{pH}$ 5.0.

In neutral sample solutions ( $\mathrm{pH} 7.0)$, the mean particle size of both bLf and

$$
-7-
$$


1 SLs was roughly $10 \mathrm{~nm}$ (Fig. $2 \mathrm{~d}$ and e). This indicates that bLf and SLs dissolved well

2 in the solutions. On mixing, they had a tendency to form aggregates of about $17 \mathrm{~nm}$ (Fig.

3 2f). The isoelectric point of bLf is $\mathrm{pH} 8.8$ (Moore et al. 1997; Shimazaki 1993), making

4 the protein positively charged at $\mathrm{pH} 5.0$ and $\mathrm{pH} 7.0$ and giving it a tendency to bind to

5 negatively charged molecules in solutions with these $\mathrm{pH}$ values. At $\mathrm{pH} 5.0$ or higher, the

6 solubility of SLs increases with increasing $\mathrm{pH}$, which is closely related to the

7 electrolytic dissociation of the linked hydroxyl fatty acids (Fig. 1) (Hu and Ju 2001; Van

8 Bogaert et al. 2011). A similar tendency was also observed for the SLs used in this study.

9 These data suggest that SLs are negatively charged both at $\mathrm{pH} 5.0$ and at $\mathrm{pH} 7.0$.

10 Therefore, it is reasonable that bLf would interact with SLs to form complexes under

11 the tested conditions. bLf contains 101 basic amino acid residues such as His, Lys, and

12 Arg that can interact with the hydroxyl fatty acid residue of SLs. Since the molar ratio

13 of bLf and SLs was approximately 1:125, all the basic residues, though not exposed to

14 the aqueous phase, can be potentially capped by adequate amounts of SLs by

15 electrostatic interactions.

3.2. Microstructure

To gain insight into the structural features of the possible complexes, Cryo-SEM was conducted to observe bLf or/and SLs present in the sample solutions. Fig. 3a describes Cryo-SEM images obtained from the sample solutions at $\mathrm{pH} 5.0$ containing $0.1 \mathrm{wt} \%$ of bLf, SLs, or a combination of bLf and SLs. bLf had a weed-like fibrous structure (A) that did not seem to aggregate. SLs self-organized into a ribbon-like architecture (B), as reported by Zhou et al. (2004), and fibrous networks (C). In solutions where bLf and SLs existed together, well-structured sheet-like materials (D) were prominantly observed. The structures formed by bLf, SLs, and bLf and SLs were 
1 observed in most fields of view. Our results suggest that bLf and SLs form continuous

2 giant complexes, similar to the original self-assembly of SL molecules reported

3 previously (Zhou et al. 2004), and do not appear to form a significant amount of

4 vesicle-like complexes.

5 Fig. 3 b shows the Cryo-SEM micrographs of the sample solutions at $\mathrm{pH} 7.0$.

6 Unlike the results shown in Fig. 3a, similar structures were found in bLf, SLs and

7 solutions containing bLf \& SLs. However, on magnification, some small sheet-like

8 structures were seen in the SLs solution (E). Additionally, at the low magnification

$9 \quad(1,000 x)$, the fibrous network in SLs appeared to be finer than the bLf network, while in

10 solutions containing a mixture of bLf and SLs, the width of the fibrous network ranged

11 between the width observed in the bLf and SLs solutions. Therefore, we can assume that

12 in neutral solutions, SLs interact with bLf to form relatively small complexes that

13 depend on electrostatic attractions (Fig. 2f), but does not induce significant changes in

14 the bLf structures. Since the interactions were not strong, it was not possible to identify

15 them under the microscope. Therefore, in order to further investigate interactions

16 between bLf and SLs, a biochemical enzymatic digestion was carried out.

\subsection{Proteolysis}

Based on research by Brines and Brock (1983), enzymatic digestions were

20 performed to confirm the structural properties of bLf-SLs complexes. If bLf is included

21 in the vesicle-like self-organization of SLs then it would be quite resistant to proteolytic degradation and would remain structurally intact. Fig. 4 shows SDS-PAGE profiles of

23 enzymatically-digested bLf using Protease $\mathrm{K}$ and a pancreatic trypsin under weakly

24 acidic and neutral conditions with or without SLs. The concentration of bLf and SLs 
1 were $0.1 \mathrm{wt} \%$. In acidic $\mathrm{pH}$ and in the absence of SLs, bLf was extensively digested by

2 Protease K and trypsin (Fig. 4a). However, in the presence of SLs, specific undigested

3 fractions of bLf were generated on treatment with Protease K and trypsin (Fig. 4b). At

4 neutral $\mathrm{pH}$, both enzymes also efficiently digested bLf in the absence of SLs (Fig. 4c),

5 whereas there were clear undigested protein bands in Protease K-treated or

6 Trypsin-treated samples (Fig. 4d). These results indicate that bLf interacted with SLs

7 but was not completely protected by the surrounding SLs. These results also support the

8 Cryo-SEM observations that bLf was not incorporated into vesicles organized by SLs

9 but was associated with the ribbon-like self-organization that occurred at $\mathrm{pH} 5$ (Fig. 3a)

10 and the network-like self-organization that occurred at $\mathrm{pH} 7$, and was mostly exposed to

11 the aqueous phase in both structures. In addition, the digestion patterns at $\mathrm{pH} 7.0$ and

$12 \mathrm{pH} 5.0$ were quite different, supporting the observation that bLf was incorporated into

13 different structures at these two pHs (Fig. 3a, 3b).

\subsection{Tertiary structural changes}

To investigate tertiary structural changes in bLf caused by SLs, the surface hydrophobicity of bLf in the presence of SL molecules was evaluated using ANS-Na as a fluorescent probe. This type of approach is often used for estimating the conformational change in globular proteins caused by heat treatment, interaction with

20 lipid membranes, etc. (Haynes and Staerk 1974; Alizadeh-Pasdar and Li-Chan 2000;

21 Haweet et al. 2008). Since lactoferrin is a globular protein, inner hydrophobic sites tend to not be exposed to the hydrophilic phase in the aqueous solution. If conformational changes induced by environmental factors, such as heat, or chemical factors, such as

24 protein-surfactant attractive interactions, result in exposure of hydrophobic residues, 
1 ANS-Na binding to the exposed hydrophobic sites can significantly increase ANS 2 fluorescence (De et al. 2005). The hydrophobicity indexes of bLf, SLs, and bLf + SLs 3 were defined as the slopes obtained from the ANS fluorescence vs bLf, SLs, and bLf + 4 SLs concentration curves (Kato and Nakai 1980; Hayakawa and Nakai 1985). The 5 hydrophobicity index obtained from the bLf solution at $\mathrm{pH} 5.0$ was significantly 6 different from that of the solution containing both bLf and SLs ( $t$-test, $p<0.05)$. The 7 values for the bLf solution and the solution containing both bLf and SLs were $370.7 \pm$ $8 \quad 1.6$ and $1092.3 \pm 71.7$, respectively (Fig. 5a). Similarly, at $\mathrm{pH} 7.0$, the hydrophobicity 9 index of the solutions containing both bLf and SLs $(478.1 \pm 25.8)$ was much higher than the solution containing only bLf $(222.4 \pm 3.4)$ (Fig. 5b)

If bLf and SLs did not interact with each other in the bLf + SLs solution, the

\subsection{Secondary structural changes}

Fig. 6 describes the CD spectra of the bLf solutions with and without SLs in acidic and neutral conditions. At pH 5.0, wavelength-dependent molar ellipticity of solutions containing only bLf ranged between approximately $-10,000$ to $0 \mathrm{deg}-\mathrm{cm}^{2} / \mathrm{dmol}$ (Fig. 6a and b), similar to the result described by Hu et al. (2008). The CD spectrum of bLf at pH 5.0 did not change significantly on addition of SLs (Fig. 6a). This indicates 
1 that at $\mathrm{pH} 5.0$, binding of SLs to bLf is not strong enough to cause marked changes in

2 the secondary structures of bLf. Similarly, at neutral $\mathrm{pH}$, addition of SLs into the bLf

3 solutions did not cause marked changes in the CD spectrum, (Fig. 6b), indicating that at

4 neutral $\mathrm{pH}$, interactions between bLf and SLs are as mild as those observed in the $\mathrm{pH}$

$5 \quad 5.0$ solution.

6

7 4. Conclusions

8 Under acidic and neutral conditions, bLf is associated with the fibrous

9 self-organization of SLs, with continuous exposure to the aqueous phase. The size and

10 shape of the bLf-SLs complexes that form at $\mathrm{pH} 5.0$ and $\mathrm{pH} 7.0$ vary significantly. The

11 positively charged bLf and the negatively charged SLs seem to form a complex via

12 electrostatic interactions, but the interactions are not strong enough to alter its secondary

13 structure. 
1 References

2 Alizadeh-Pasdar, N., and Li-Chan, E. C. Y. 2000. Comparison of protein surface hydrophobicity measured at various $\mathrm{pH}$ values using three different fluorescent probes. J. Agric. Food Chem. 48: 328-334.

Brines, R. D., and Brock, J. H. 1983. The effect of trypsin and chymotrypsin on the in vitro antimicrobial and iron-binding properties of lactoferrin in human milk and bovine colostrum. Unusual resistance of human apolactoferrin to proteolytic digestion. BBA - Gen. Subj. 759: 229-235.

De, S., Girigoswami, A., and Das, S. 2005. Fluorescence probing of albumin-surfactant interaction. J. Colloid Interface Sci. 285: 562-573.

Fasman, G. D. 1978. Circular dichroism analysis of chromatin and DNA-nuclear protein complexes. In Methods in cell biology, vol 18: Chromatin and chromosomal protein research III, eds. Gary Stein, Janet Stein, and Lewis J. Kleinsmith. New York: Academic pree, Inc., p. 327-350.

Groves, M. L. 1960. The isolation of a red protein from milk. J. Am. Chem. Soc. 82:3345-3350.

Hawe, A., Sutter, M., and Jiskoot, W. 2008. Extrinsic fluorescent dyes as tools for protein characterization. Pharm. Res. 25: 1487-1499.

Hayakawa, S. S., and Nakai, S. 1985. Relationships of hydrophobicity and net charge to the solubility of milk and soy proteins. J. Food Eng. 50: 486-491.

Haynes, D. H., and Staerk, H. 1974. 1-Anilino-8-naphthalenesulfonate: a fluorescent probe of membrane surface structure, composition and mobility. J. Membr. Biol. 17: 313-340.

Hu, F., Pan, F., Sawano, Y., Makino, T., Kakehi, Y., Komiyama, M., et al. 2008. Studies 
of the structure of multiferric ion-bound lactoferrin: A new antianemic edible material. Int. Dairy J. 18: 1051-1056.

Hu, Y., and Ju, L. K. 2001. Purification of lactonic sophorolipids by crystallization. J. Biotechnol. 87 :263-272.

Imura, T., Morita, T., Fukuoka, T., Ryu, M., Igarashi, K., Hirata, Y., et al. 2014. Spontaneous vesicle formation from sodium salt of acidic sophorolipid and its application as a skin penetration enhancer. J. Oleo Sci. 63: 141-147.

Ishii, N., Kobayashi, T., Matsumiya, K., Ryu, M., Hirata, Y., Matsumura, Y., et al. 2012. Transdermal administration of lactoferrin with sophorolipid. Biochem. Cell Biol. 90: 504-512.

Kato, A., and Nakai, S. 1980. Hydrophobicity determined by a fluorescence probe method and its correlation with surface properties of proteins. Biochim. Biophys. Acta - Protein Struct. 624: 13-20.

Konishi, M., Fukuoka, T., Morita, T., Imura, T., and Kitamoto, D. 2008. Production of new types of sophorolipids by Candida batistae. J. Oleo Sci. 57: 359-369.

Lang, S. 2003. Surfactants produced by microorganisms. In Novel surfactants: Preparation applications and biodegradability, second edition, revised and expanded, Surfactant Science, ed. Krister Holmberg. New York, USA: CRC Press, p. 279-316.

Lönnerdal, B., and Suzuki, Y. A. 2013. Lactoferrin. In Advanced Dairy Chemistry Volume 1A: Proteins: Basic Aspects, eds. Paul L. H. McSweeney and Patrick F. Fox. New York, USA: Springer, p. 295-315.

Moore, S. A., Anderson, B. F., Groom, C. R., Haridas, M., and Baker, E. N. 1997. Three-dimensional structure of diferric bovine lactoferrin at $2.8 \AA$ resolution. J. 
1

2 Nuñez, A., Ashby, R., Foglia, T. A., and Solaiman, D. K. Y. 2001. Analysis and 3

Mol. Biol. 274: 222-236. characterization of sophorolipids by liquid chromatography with atmospheric pressure chemical ionization. Chromatographia. 53: 673-677.

Shimazaki, K. 1993. Analysis of Human and Bovine Milk Lactoferrins By Rotofor and. 25: $1653-1658$.

Sørensen, M. and Sørensen, S.P.L. (1939). The protein in whey. C. R. Trav. Lab. Carlsberg 23: 55-99.

Tang, L., Wu, J.J., Ma, Q., Cui, T., Andreopoulos, F.M., Gil, J., et al. 2010. Human lactoferrin stimulates skin keratinocyte function and wound re-epithelialization. Br. J. Dermatol. 163(1): 38-47.

Van Bogaert, I. N. A., Zhang, J., and Soetaert, W. 2011. Microbial synthesis of sophorolipids. Process Biochem. 46: 821-833.

Zhou, S., Xu, C., Wang, J., Gao, W., Akhverdiyeva, R., Shah, V., and Gross, R. 2004. Supramolecular assemblies of a naturally derived sophorolipid. Langmuir, 20(19): 7926-7932. 
1 Figure captions

2

3 Fig. 1. Chemical structure of an SL.

4 Molecular weight of the displayed chemical compound is $622 \mathrm{Da}$.

5

6 Fig. 2. Particle size distributions of bLf, SLs, and bLf + SLs mixtures under acidic (a-c)

7 and neutral (d-f) conditions with a volume-weighted mean diameter.

9 Fig. 3. Cryo-SEM images of pH 5.0 and pH 7.0 aqueous solutions of bLf, SLs, and bLf $10+$ SLs.

Fig. 4. SDS-PAGE patterns of bLf digested by proteolytic enzymes with or without SLs. Enzymatic treatments were carried out at $37^{\circ} \mathrm{C}$ for 30,60 , and $90 \mathrm{~min} . \mathrm{M}, \mathrm{C}$, and the numbers shown above the gels refer to molecular weight markers $(M)$, untreated bLf under the specified $\mathrm{pH}$ conditions serving as a control $(\mathrm{C})$, and the incubation time in minutes with Protease K or trypsin. The concentrations of bLf and SLs were $0.1 \mathrm{wt} \%$.

Fig. 5. Surface hydrophobicity of bLf, SLs, and bLf + SLs under acidic and neutral conditions.

Hydrophobicity indexes were calculated based on the slopes of fluorescence intensity vs sample concentration curves. Data are expressed as mean \pm standard deviation $(n=3)$.

Fig. 6. CD spectra of the $\mathrm{pH} 5.0$ and $\mathrm{pH} 7.0 \mathrm{bLf}$ and bLf-SLs solutions. Measurements 
1 were performed at $25^{\circ} \mathrm{C}$ on a spectropolarimeter using a quartz cell with $0.1 \mathrm{~mm}$ optical

2 path length. Values are expressed as the mean of the data obtained from three samples,

3 with measurements repeated three times for each sample. 
$1 \quad$ Figure 1

2

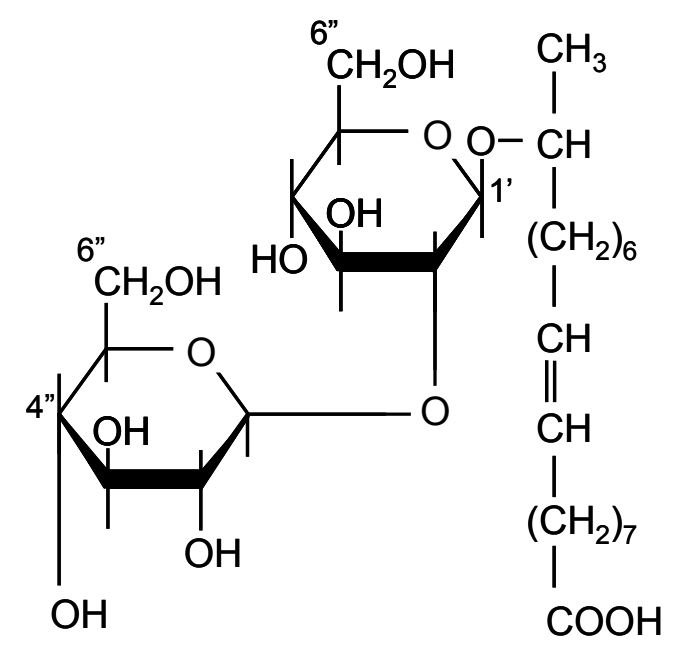


$1 \quad$ Figure 2

pH 5.0

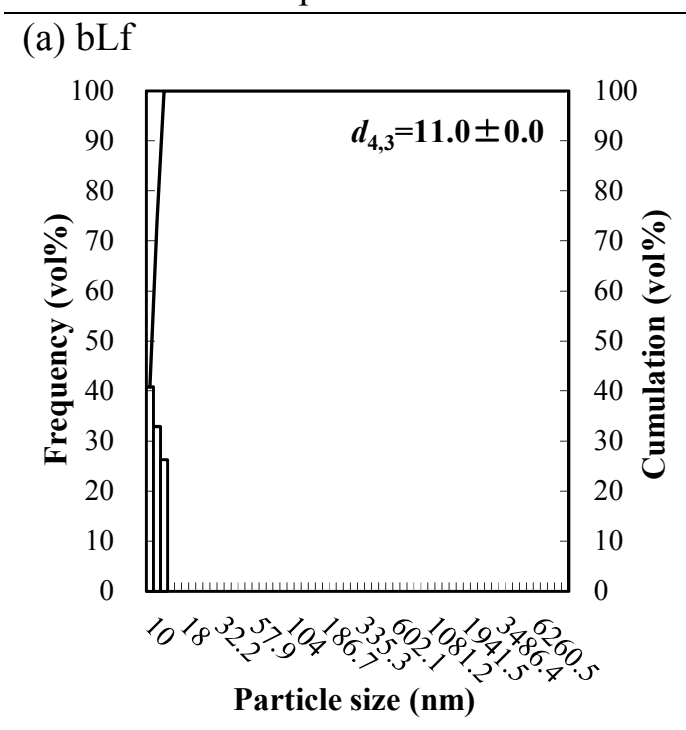

(b) SLs

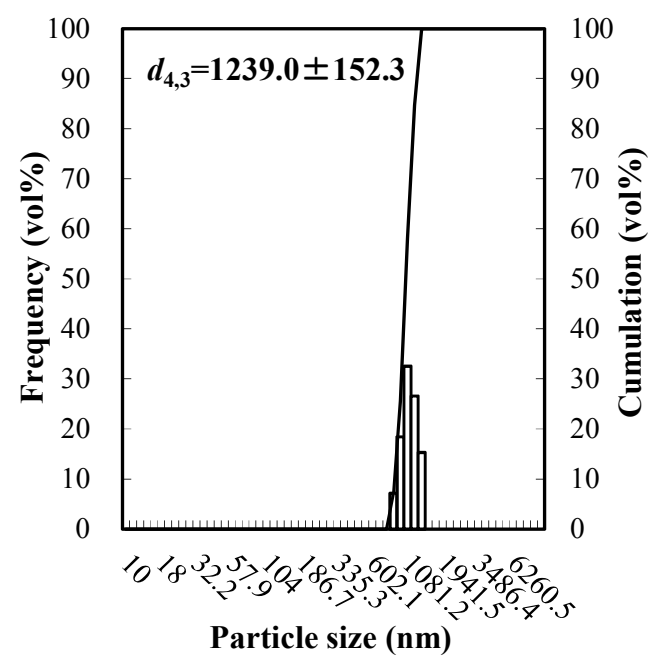

(c) bLf \& SLs

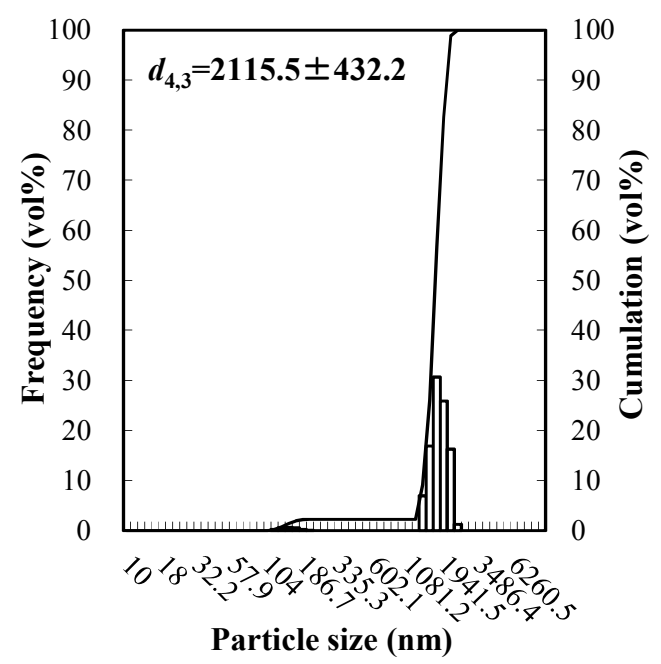

pH 7.0

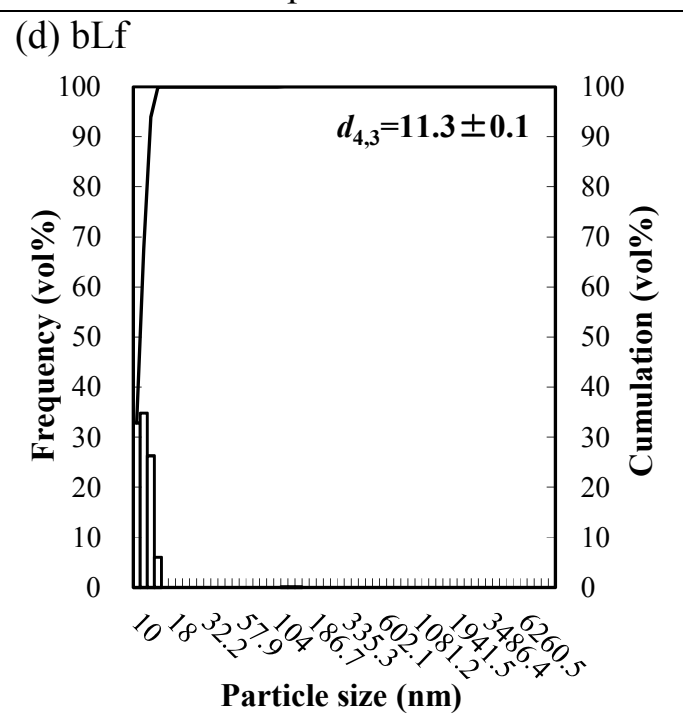

(e) SLs

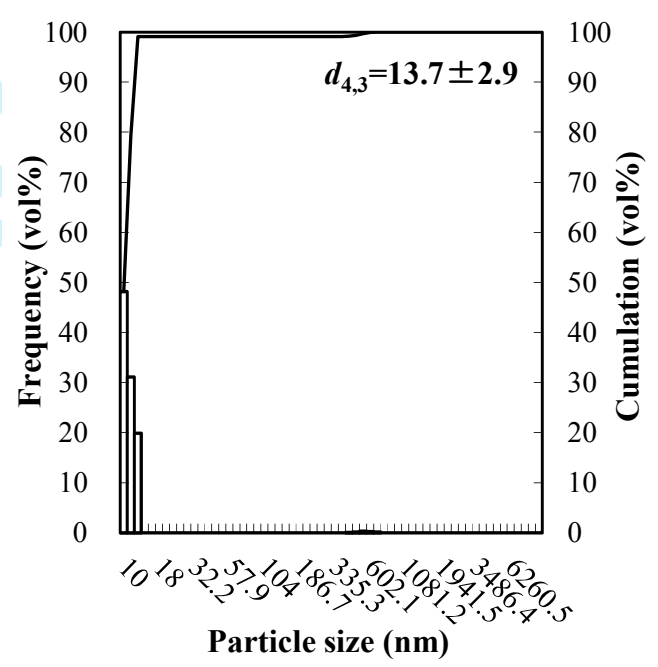

(f) bLf \& SLs

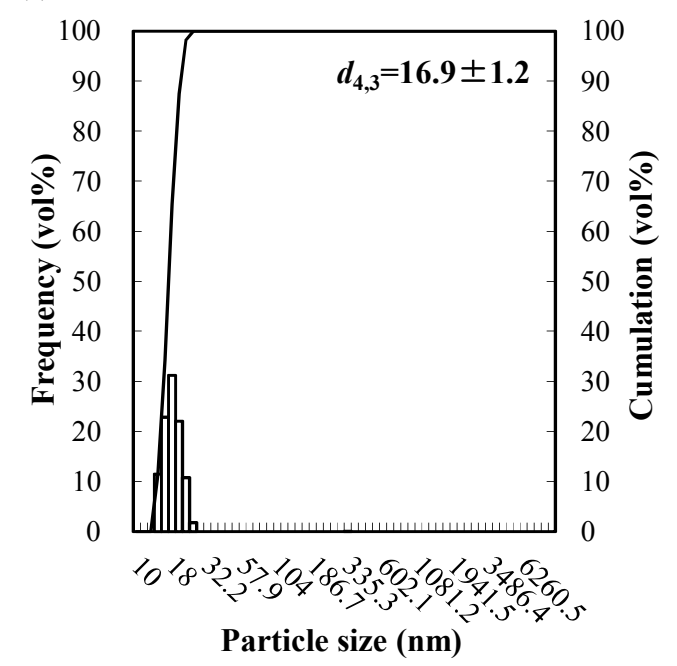


$1 \quad$ Figure 3

(a) $\mathrm{pH} 5.0$

bLf

SLs

bLf \& SLs x 1,000
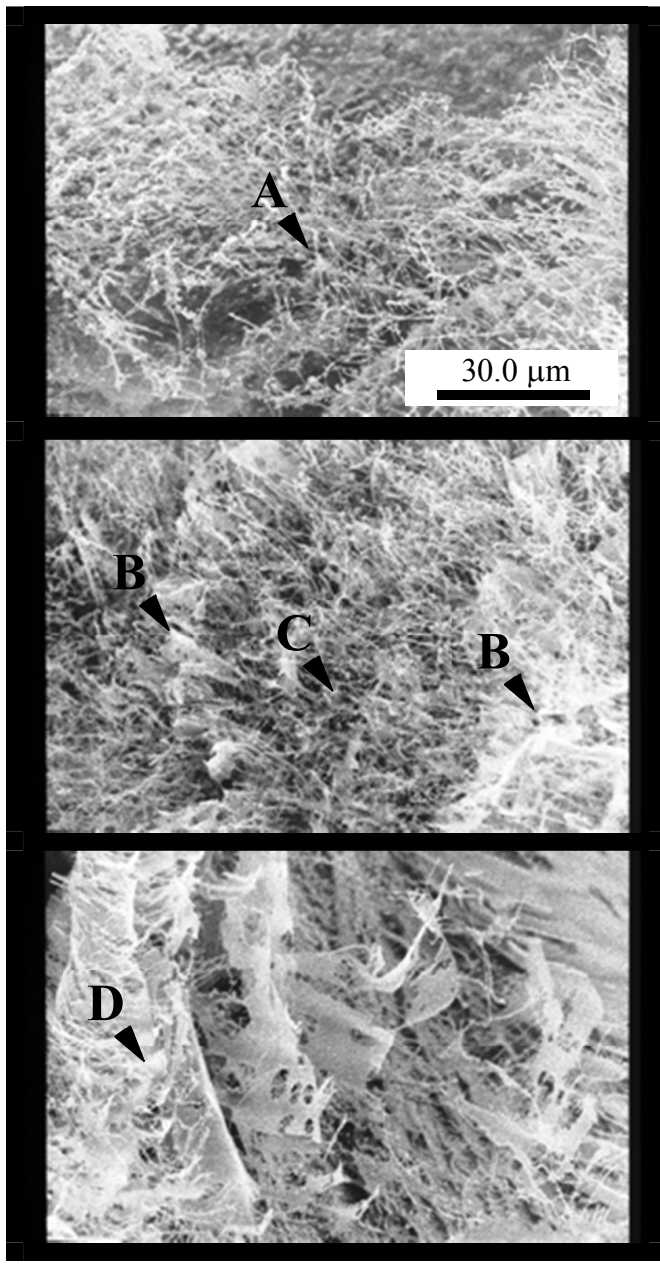

x 3,000

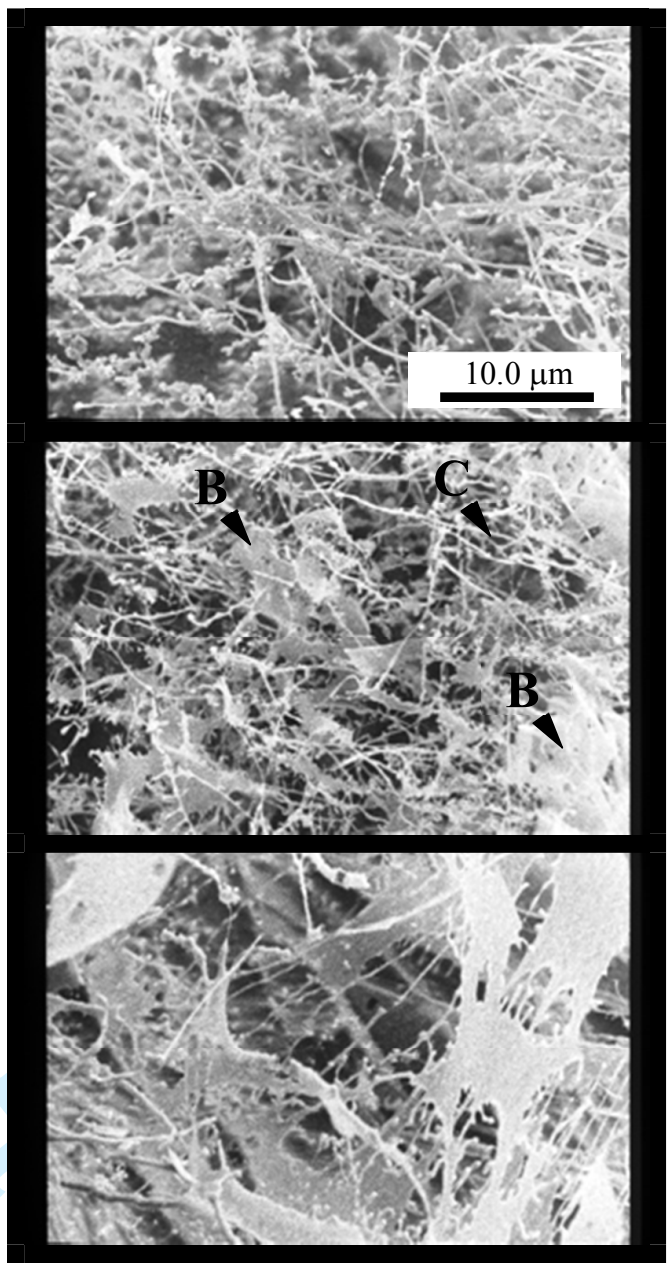


$1 \quad$ Figure 3 (continued)

(b) $\mathrm{pH} 7.0$

bLf

SLs

bLf \& SLs
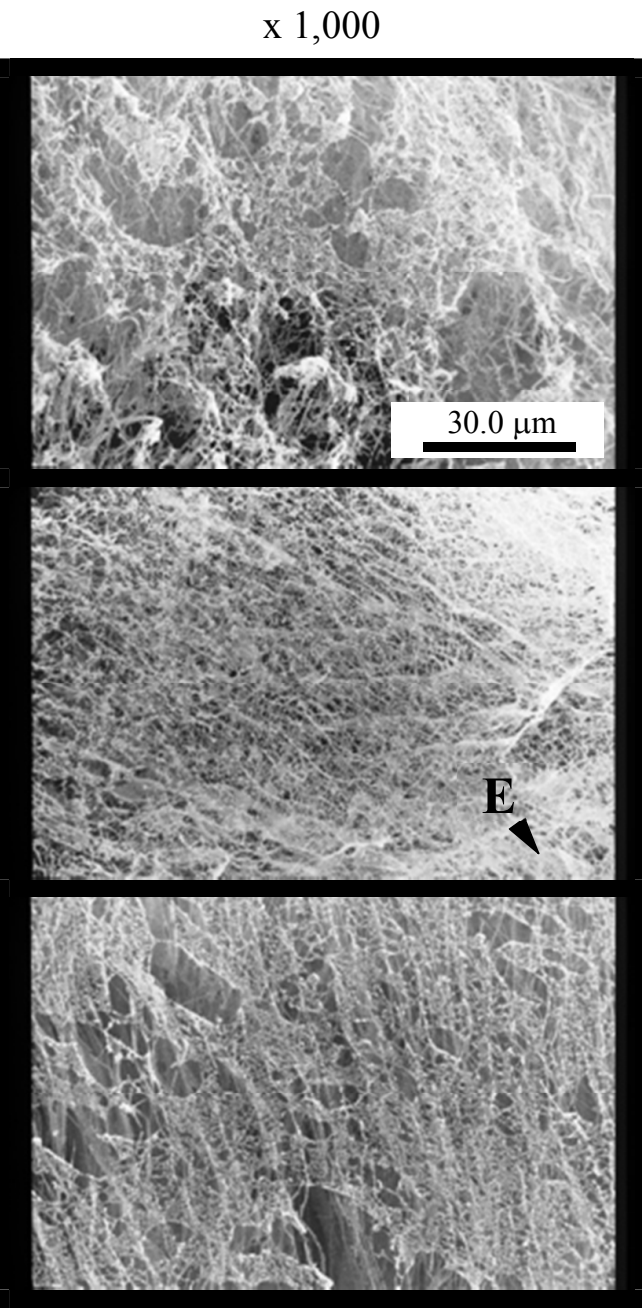

x 3,000

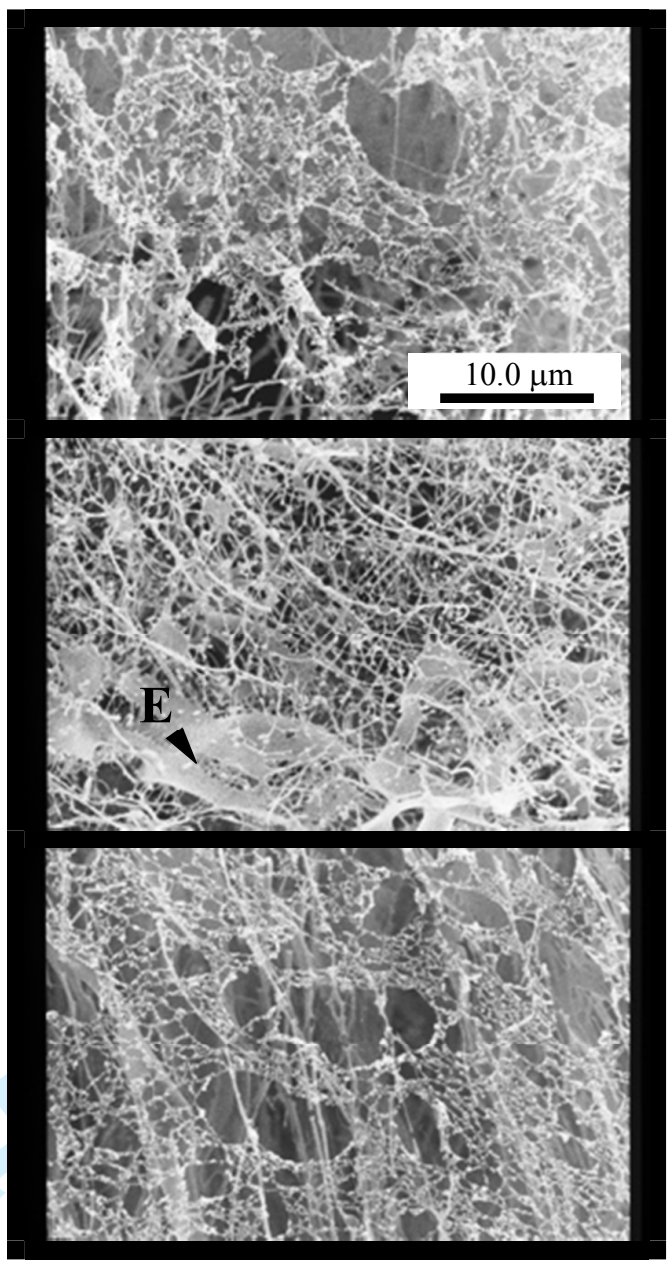


$1 \quad$ Figure 4

pH 5.0

(a) bLf

(b) bLf \& SLs
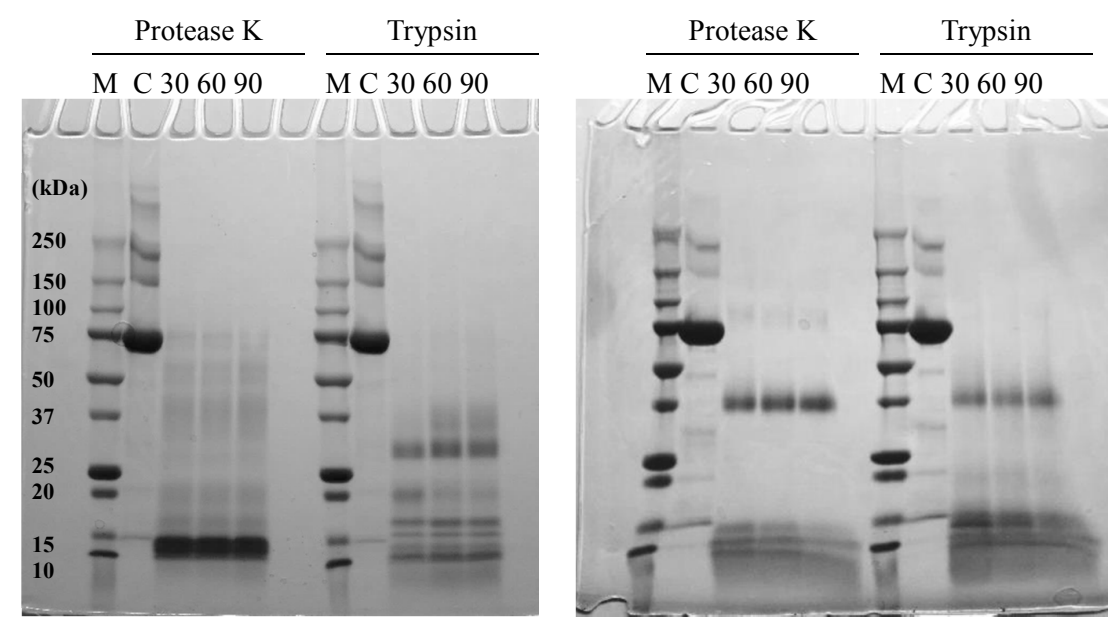

pH 7.0

(c) bLf

(d) bLf \& SLs
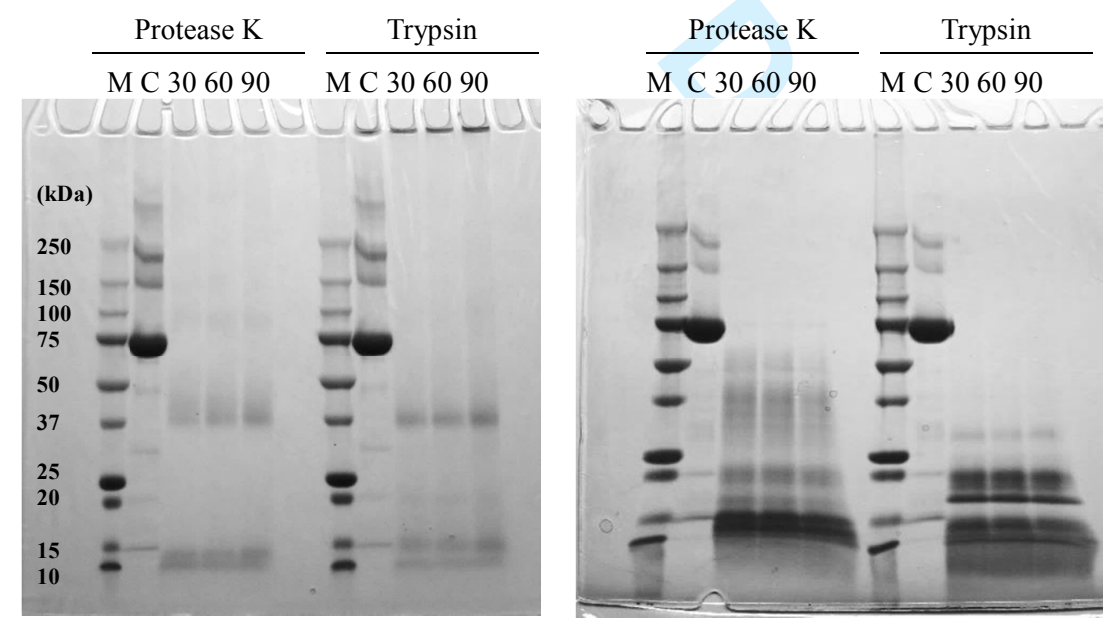

2 
1 Figure 5

$2 \quad$ (a) $\mathrm{pH} 5.0$

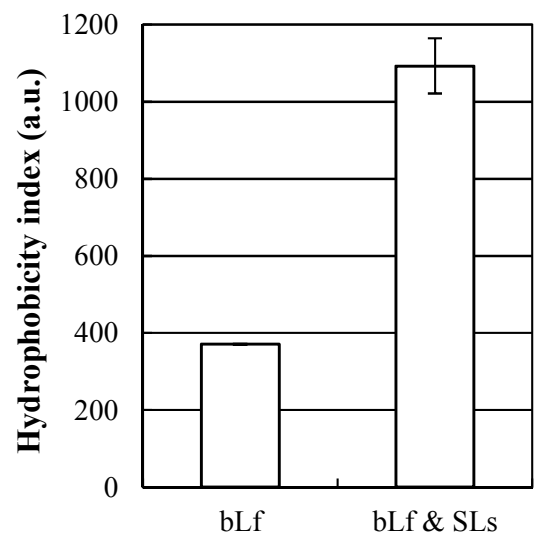

3

(b) $\mathrm{pH} 7.0$

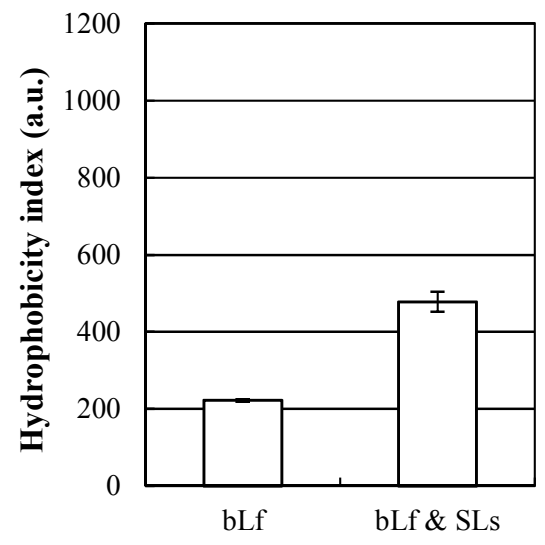

5 
1 Figure 6

2 (a) $\mathrm{pH} 5.0$

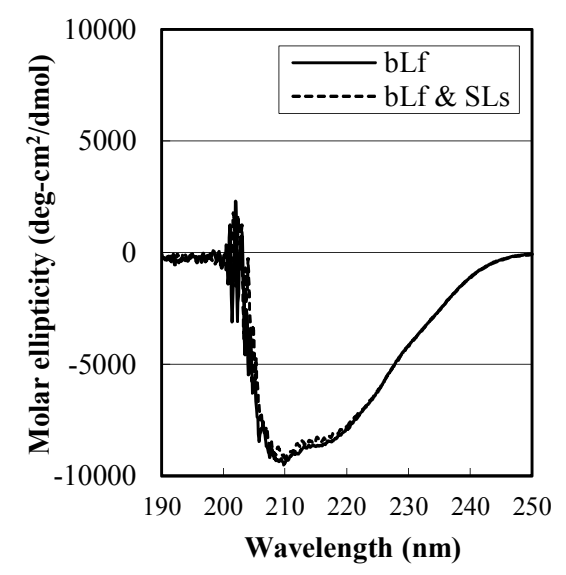

$4 \quad$ (b) $\mathrm{pH} 7.0$

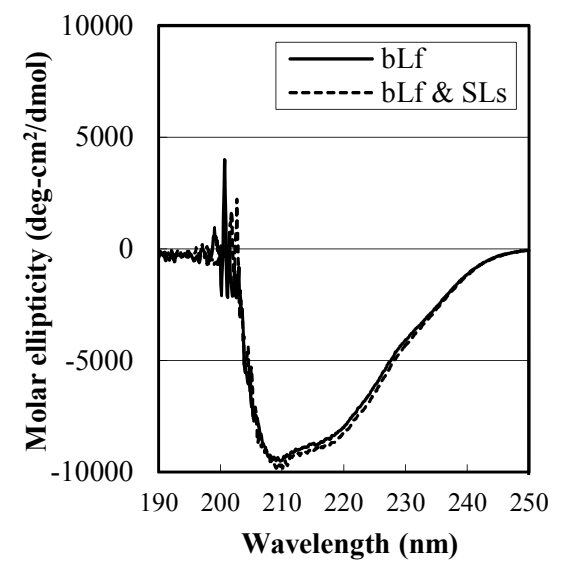

